\title{
Neonatal nurse practitioners-a view from perfidious Albion?
}

\author{
M A Hall, S L Smith, J E Jackson, E M Perks, P Walton
}

\begin{abstract}
Although the professional role of neonatal nurse practitioners (NNPs) has been fully integrated into many neonatal units outside the UK over the past decade, ${ }^{12}$ there has to date been no such development in this country. Indeed, there have been serious reservations among members of the neonatal nursing profession concerning the introduction of NNPs given the current structure and funding of neonatal care in the UK. ${ }^{3}$

Despite these reservations, it has for several years been the view of most of the paediatricians and of many neonatal nurses within the Wessex region that the care of sick newborn infants could be improved by extending the role of the neonatal nurse. The case for extending the role has now been accepted by medical and nurse managers within the region and plans are well advanced to establish an educational course in Southampton for the development of NNPs in Wessex.

In planning this radical innovation it was felt that much could be learnt, and many problems possibly avoided, by examining the training and professional role of NNPs in North America. A study visit of six selected North American neonatal units and NNP training programmes was, therefore, undertaken by a group consisting of one paediatrician and four senior neonatal nurses. The two main aims of the visit were: (i) to study the NNP training programmes and (ii) to evaluate the clinical role of NNPs working in neonatal intensive care units.
\end{abstract}

Department of Neonatal Medicine, Princess Anne Hospital, Coxford Road, Southampton SO9 4HA M A Hall

$S$ L Smith

E $M$ Perks

P Walton

Neonatal Unit,

Royal United

Hospital, Bath

J E Jackson

Correspondence to: Dr Hall. decided to evaluate three master's courses and three certification courses (table 1). Identical information was collected from each unit and the following represents a synopsis of our findings.

\section{(1) Origins of NNPs}

NNPs seem to have been introduced into neonatal units in North America in the early 1970s. At about this time a formal study of the role development of the neonatal nurse was undertaken as part of a master's thesis by a nursing student. ${ }^{45}$ This study is widely credited as forming the basis for the development of NNP programmes and the student who undertook the study, Patricia Johnson, is regarded by many as being the 'original neonatal nurse practitioner'.

Formal training programmes, however, did not become widely available until the early to mid 1980s. The introduction of NNPs was welcomed by many neonatologists in North America as being the only effective way of dealing with the ever increasing neonatal workload. Financially, there was clearly pressure on institutions to provide a neonatal intensive care service as this is a lucrative source of income for many hospitals; the introduction of NNPs has now provided an effective and reasonably economic source of skilled staffing for these units.

From the nurse's point of view there has been a widespread belief that extending the role of the neonatal nurse provides an effective, and at times superior, alternative to the variable standard and quality of care which relatively undertrained resident medical staff may provide. However, for this extended role to be acceptable to nurses of appropriate calibre it has been essential that in-depth training and education should be provided and that the new role should be seen by the profession as a genuine career advancement.

Although many courses have been initiated as certification programmes there has been a definite shift in emphasis from 'training' to 'education' and simultaneously a recognition that the nurse practitioner provides a different and possibly more holistic type of care than her medical practitioner colleagues. In recognition of these changes in role development and educational needs many programmes now award a master's degree after completion.

Table 1 Neonatal units visited

\begin{tabular}{ll}
\hline Neonatal unit & Type of programme \\
\hline Georgetown University, Washington DC DC & Certification \\
Samaritan College of Nursing, Phoenix, Arizona & Certification \\
St John's Mercy Medical Center, St Louis & Certification \\
University of Texas Health Sciences Center & Master's degree \\
Primary Childrens Medical Center, Salt Lake City, Utah & $\begin{array}{l}\text { Master's degree } \\
\text { Rush University, Chicago }\end{array}$ \\
\hline
\end{tabular}


(2) Training programmes in North America (A) DESIGN AND CONTENT OF THE COURSE In order to be registered as qualified NNPs by the National Certifying Council (NCC) candidates must have successfully completed a certified NNP training programme and examination. The full time courses that we evaluated range in length from nine months to two years; in addition two centres offer part time courses that can extend up to five years. Most training programmes are jointly directed by a coordinator-usually a nurse with a master's degree-and a neonatologist. The courses are divided into a period of classroom based teaching (didactic) followed by a clinical apprenticeship (preceptorship).

A recent survey of existing programmes by the Special Interest Group of NANN found the minimum total course length to be nine months with at least 320 hours of theoretical teaching. This is then followed by the supervised clinical apprenticeship of at least 800 hours, which is usually undertaken in the sponsoring unit. The theoretical teaching includes the full range of neonatal medicine in a depth probably equivalent to that which would be covered by paediatric registrars during their training in this country. Lecturers include neonatologists, radiologists, physiologists, pharmacists, NNPs, and other specialists. Examples of the minimum number of didactic teaching hours are as follows: respiratory system, 38 hours; metabolic/ endocrine system, 23 hours; and cardiovascular system, 20 hours.

In addition to the theoretical component, training in practical skills is provided for the procedures shown in table 2 . It is the responsibility of the mentor to ensure that the student achieves a satisfactory level of clinical competence before graduation. Some units stipulate minimum numbers of procedures which should be successfully completed before qualifying. However, in some cases difficulties have been experienced when targets are set, but not achieved, before graduation. In these instances, the base unit is informed and this is highlighted as an area needing continued focus and attention after graduation. A variety of teaching aids and methods are used, including infant models and live animals (cats and rabbits); the latter are used in some but not all centres. The clinical apprenticeship is in all cases supervised by a neonatologist, but qualified NNPs are used as mentors and for role modelling and role development.

Table 2 Practical procedures

\begin{tabular}{ll}
\hline Procedure & $\begin{array}{l}\text { Minimum No } \\
\text { required in } \\
\text { some units }\end{array}$ \\
\hline Endotracheal intubation & 10 \\
Arterial sticks (stabs) & 5 \\
Suprapubic taps & 5 \\
Lumbar punctures & 5 \\
Chest drain insertion & 3 \\
Needle aspiration of the chest & 3 \\
Insertion of peripheral cannulae & None specified \\
Insertion of arterial cannulae & None specified \\
Insertion of umbilical arterial catheter & None specified \\
Insertion of umbilical venous catheter & None specified \\
\hline
\end{tabular}

(B) EVALUATION OF THE STUDENTS

All of the units visited use a combination of written examinations and clinical assessments. Many programmes also have weekly quizzes, case presentations, and project assignments. Clinical logs are widely used during the apprenticeship. Clinical evaluation of the students requires collaboration between the course coordinator, the student's mentor, and the neonatologist in charge of the unit in which the clinical apprenticeship takes place. Newly qualified NNPs are often teamed up with an experienced NNP or 'buddy' whom they work alongside for the first few months in their new role.

\section{(c) FUNDING OF THE STUDENTS}

Course fees and salaries are usually paid by the hospital in which the NNP student was previously employed. In many cases there is a formal agreement that, after qualification, the NNP will return to work in the sponsoring hospital for a specified period, usually two years. The incentive to become a NNP, however, is sufficient for some students to fund themselves during their training and most students accept a drop in salary while training. Students who are self funding often support themselves by working at weekends and during holidays.

(D) QUALIFICATIONS, QUALITIES, AND

MOTIVATION OF THE STUDENTS

In order to be accepted onto a NNP training course students are usually required to have a minimum of two years' experience in neonatal nursing. In practice most student NNPs have at least four years' previous experience. Students are expected to be 'well above average academically' and a letter of recommendation is required from the neonatologist in charge of the student's base unit. Although personal interviews are not always held the following qualities are sought in potential NNPs: assertiveness, flexibility, leadership, communication skills, and the ability to handle stress.

For the experienced neonatal nurse the role of the NNP seems to offer autonomy, the ability to advance clinically and not into management, and the opportunity to acquire a more detailed understanding of neonatology.

\section{(3) The role of the NNP}

In most units NNPs are responsible to the fellow or attending neonatologists in their clinical role and to senior nursing colleagues in their educational role. It was reported by both medical and nursing staff that NNPs function at a level equivalent at least to a second or third year resident and, in some cases at the level of a fellow. Although the level of functioning of the NNP is equivalent to that of residents, prescriptions or orders are usually countersigned by medical staff within a set time. In most units, NNPs do not undertake the more traditional functions of staff nurses on neonatal units and it was suggested in more than one unit that it is 
not feasible for a highly trained NNP routinely to provide all of the nursing care required by sick neonates. However, it was stressed to us that a holistic approach is very important in the education of other members of the care team. In most units NNPs have their own caseloadsusually up to seven intensive care babies.

The NNP is expected to 'clerk in' patients, initiate appropriate management in conjunction with senior neonatal medical staff, and be responsible for the subsequent day to day clinical management. The NNP team often maintain responsibility for the babies they admit and are usually responsible for discharge planning. The working arrangements are variable and range from 10 hours each day, four days per week to a 24 hour on call system. In those units where 24 hour NNP cover is provided, it was reported that there is improved continuity of care and more job satisfaction. In more than one unit it was stated that NNP rotas are planned in conjunction with the medical rota, to ensure that if the medical staff cover is relatively inexperienced then a qualified NNP will be available on the unit. It was felt that this provides the best possible blend of experience. In most units the NNP teams are self scheduling and within their care teams they are expected to provide cover for each other if any problems with sickness or off duty requests arise.

The extent to which protocols are used varies from unit to unit, but it is generally accepted that they are used as guidelines only and should not be too detailed or prescriptive as legal problems may ensue if they are not followed exactly. In most units NNPs are involved in formulating both medical and nursing protocols which are usually endorsed by the neonatologist.

'Sharing of skills and considerable mutual support' was reported to be an important interaction between NNPs and residents, and although there is no formal role in teaching residents, it is generally accepted by the medical staff that NNPs do have an important educational role in ward teaching and they are seen as a vital resource for all members of the caring team. An awareness of potential difficulties in staff relationships was reported, particularly between NNPs and the other neonatal nurses; these problems are addressed during the training courses. However, it was unanimously reported by both doctors and nurses that NNPs have been welcomed by all members of staff and that no serious problems have occurred. We encountered no antipathy or jealousy between NNP and residents, who had seen their workload decrease and felt that they could learn from NNPs. Many staff nurses preferred NNPs to be responsible for the babies in their care as they felt there was improved continuity of care and they were able to learn from the NNP. From all areas the introduction of NNPs has been positively accepted and everyone spoke highly of their professionalism and the importance of their presence on the caring team. It was stressed that the role should be clearly defined from the outset, not only to help other staff nurses on the neonatal unit, but also to enable the recently qualified NNP find her new profes- sional identity. One potential problem for trained NNPs is that they may be unable to maintain their skill levels if they work in nurseries with only limited intensive care facilities. To overcome this in some units NNPs working in level II nurseries rotated into level III nurseries and the NNP can also attend ward rounds in the intensive care units. Once qualified, almost without exception NNPs stay in the clinical area and the rate of attrition is very low. It is accepted that this is a job that nurses want to stay in for many years and that within the role there is scope for expansion, for example into clinical teaching or research.

The NCC have stipulated that NNPs should receive $\mathbf{4 5}$ hours of continuing education during each three year period to qualify for recertification. This may include attendance at weekly rounds (after prior agreement with the board of NCC) and attendance at local or national conferences and journal clubs. The provision of funding for attendance at national conferences varies from unit to unit: in some cases the hospital pay the full fees while in others up to $80 \%$ of the registration fees is paid but hotel accommodation and travel fees must be paid by the NNP.

Salaries are reported to range from $\$ 27000$ $\$ 70000$, teaching hospitals usually pay less than smaller units. Some units stated that initially there had been difficulties in obtaining increased funding for NNPs. This was thought to be due to the fact that most administrators and some nursing colleagues had no understanding of the extent of the role and the degree of responsibility it encompasses.

With regard to evaluation of the role there appears to be no consistency among the units. In some units the role is evaluated by the medical and nursing director and a peer review system, while in at least one unit staff nurses are required to provide a written evaluation of the NNP as a clinical resource.

\section{(4) Legal implications}

In all units legal indemnity is provided by the hospitals. It is the individual NNP's choice to decide whether or not to take out personal insurance but some institutions tend to discourage this on the grounds that this may complicate any legal proceedings. It was reported that some insurance companies are no longer willing to insure nurse-midwives or NNPs for personal liability. In stark contrast to litigation involving medical practitioners we were told by several senior members of NANN that there have been no known cases of litigation where a NNP has been cited.

\section{Discussion}

If the centres that we visited reflect the US in general there can be no doubt that the introduction of NNPs has represented a highly successful advance in the delivery of care to sick newborn infants-an advance that has been universally welcomed by both doctors and nurses. Moreover, in the pragmatic world of the privately funded health service which exists in 
the US, NNPs are financially viable because they enable hospitals to accept more patients, and therefore more funds, than would be possible if there were no NNPs. In contrast in the UK health system there is no such financial incentive to the introduction of NNPs. Indeed, many hospitals would regard any potential increase in patient load to be a good reason for not introducing NNPs as this would impose a financial burden on the institution.

Funding limitations certainly constitute an important reason for the inertia and relative indifference with which the concept of NNPs has so far been greeted in the UK but there has also been a widespread scepticism among neonatal nurses themselves concerning the advantages to the patient of extending the role of the nurse. There has been, therefore, no formal development of the extended role of the neonatal nurse in the UK and the visiting team had no previous direct experience of NNPs. With these considerations in mind we hope that the following observations will be regarded, not as criticisms, but as areas that we would hope to develop after the introduction of our own NNP training programmes.

It was implicit, although not always overtly stated, in most of the conversations that we held with both nurses and doctors that the care delivered by NNPs was undoubtedly superior to that of most first and second year residents and, in some cases, at least equivalent to that of third year paediatric residents and even fellows. This is hardly surprising given the negligible previous neonatal experience of most newly qualified doctors and the parsimonious allocation of time for neonatal training given to new residents in neonatology. The surprise, perhaps, lies in the fact that, in those hospitals in which NNPs and paediatric residents coexist, there remains such a well demarcated separation in the training of NNPs and residents. Having witnessed the impressive benefits afforded by the introduction of NNPs we feel moved to ask: why are paediatric residents in both the UK and the US still not accorded the benefit of a period of training equivalent to that of NNPs before they are required to assume a degree of clinical responsibility, and to undertaken intricate practical procedures, for which they are not adequately prepared? There are precedents for such periods of clinical training in the UK, notably in anaesthesia. Perhaps the answer lies in the financial implications involved in such a development.

In comparing the US with the UK there are important differences in medical staffing arrangements in neonatal units. First, the paediatric residents in the US - senior house officer equivalents-usually spend only one month at a time employed in the neonatal unit and, in accordance with recently revised guidelines, may receive a maximum of three to six months exposure to neonatology during their three year residency programmes. In contrast, paediatric senior house officers in training in this country are often employed continuously for six months and may spend longer at this level. Second, the clinical role of middle grade staff in the USfellows-seemed to be less well defined in comparison to their UK registrar equivalents, particularly as there is now a requirement that fellowship programmes should emphasise training in research. ${ }^{6}$ Finally the 'attending' neonatologist in the US tends to be more actively involved in the day to day running of the unit than his UK consultant counterpart, at least in many non-regional centres. There are also important differences in the training and functioning of neonatal nurses: there is no equivalent to the English National Board postregistration 405 course in the US and the training of staff nurses is probably less comprehensive than that of nurses who have completed the 405 course in this country. Such differences may be relevant to the way in which NNPs are incorporated into the UK system and it is possible that a different type of NNP may evolve in this country.

Since the original study conducted by $\mathrm{Pat}$ Johnson $^{45}$ there have been surprisingly few formal attempts at objective evaluation of NNPs to date, ${ }^{78}$ although there are now plans for an assessment to be undertaken, involving at least three centres in North America. Here, we hope that we shall be able to benefit from the experience of our visit and to explore the possibility of evaluating the effect of introducing NNPs contemporaneously with their introduction.

In the light of the recent changes in the NHS funding mechanisms, the envisaged developments in the nursing profession and the imminent decrease in the working hours of junior doctors, the time has come to review the way in which care is provided for sick newborn infants and to begin exploring the potentially important contribution which 'neonatal nurse practitioners' may make in establishing a higher level and more consistent quality of care for newborn infants. The study visit group would like to acknowledge the help of:
P Johnson, T Karp, S McCabe, C Theorell, C Trotter, and P Johnson, T Karp, S McCabe, C Theorell, C Trotter, and P Villarreal and thank the following sponsors: the Wessex
Regional Health Authority, the Allan Brooking NHS Travel Regional Health Authority, the Allan Brooking NHS Travel
Fellowship, S and W Vickers, Ivac, Wyeth Nutrition, Bliss, Milupa, Drager, Graseby, Critikon, Roussel, and Vygon.

1 Harper RG, Little GA, Concepcion GS. The scope of nursing practice in level III neonatal intensive care units. Pediatrics 1982;70:875-8

2 Sims MS, Jasani N, Yan J, Hodgman JE. Care of very low birth weight infants by neonatal nurse clinicians. 7 Perinatol 1987;7:55-7.

3 Hale P, Boxall J, Hunt $M$. The role of neonatal nurse practitioners: a viewpoint. Arch Dis Child 1987;62:760-1.

4 Johnson PJ, Jung AL, Boros SJ. Neonatal nurse practitioners: part $1-$ a new expanded nursing role. Perinatology Neonatology 1979; Jan/Feb 3:34-6.

5 Johnson PJ, Boros SJ. Neonatal nurse practitioners: part 2-implementation of a new expanded nursing role: 2-implementation of a new expanded nursing
Perinatology Neonatology 1979; Mar/Apr 3:25-7.

6 Federation of Pediatric Organisation. Statement on pediatric fellowship training. Pediatrics 1991;87:265.

7 Cassady G. Through the looking glass-or, look before you leap. Pediatrics 1982;70:1001-3.

8 Mitchell A, Watts J, Whyte R, et al. Evaluation of graduating neonatal nurse practitioners. Pediatrics 1991;88:789-94.

\section{Commentary}

The concept of the neonatal nurse practitioner (NNP) has been the focus of much informal debate within neonatal units, with a wide variety of opinion and support for the concept obvious. It is apparent from listening to these 